\title{
Renal Acid Excretion and Intracellular pH in Salt-sensitive Genetic Hypertension
}

Daniel C. Batlle, Arya M. Sharma, Mouhamed W. Alsheikha, Maria Sobrero, Abdulkarim Saleh, and Cory Gutterman

Division of Nephrology/Hypertension, Department of Medicine, Northwestern University Medical School and

Lakeside Veterans Administration Hospital, Chicago, Illinois 60611-3008

\begin{abstract}
Acid-base status and renal acid excretion were studied in the Dahl / Rapp salt-sensitive (S) rat and its genetically salt-resistant counterpart $(R)$. S rats developed hypertension while on a very high salt diet $(\mathbf{8 \%})$ and while on a more physiological salt diet $(1 \%)$ and remained normotensive while on a very low salt diet $(\mathbf{0 . 0 8 \%})$. Under the high salt diet, intracellular $\mathrm{pH}$ measured in freshly isolated thymic lymphocytes using 2',7'-bis (carboxyethyl)-5 (6)-carboxyfluorescein acetomethyl ester, a pH-sensitive dye, was lower in $S$ than in $R$ rats both when measured in the presence of $\mathrm{HCO}_{3} / \mathrm{CO}_{2}(7.32 \pm 0.02$ vs. $7.38 \pm 0.02$, respectively, $P<0.05)$ and in its absence (7.18 \pm 0.04 vs. $7.27 \pm 0.02$, respectively, $P<0.05)$. Under the high salt diet, net acid excretion was higher in $\mathbf{S}$ than $\mathbf{R}$ rats $(1,777 \pm 111$ vs. $1,017 \pm 73 \mu \mathrm{Eq} / 24 \mathrm{~h}$ per $100 \mathrm{~g}$ body wt, respectively, $P<0.001$ ), and this difference was due to higher rates of both titratable acid and ammonium excretion. Directionally similar differences in intracellular pH and net acid excretion between $S$ and $R$ rats were also observed in salt-restricted animals. In $S$ and $R$ rats placed on a normal salt intake (1\%) and strictly pair-fed to control food intake as a determinant of dietary acid, net acid excretion was also higher in $S$ than in $R$ rats $(562 \pm 27$ vs. $329 \pm 21 \mu \mathrm{Eq} / 24 \mathrm{~h}$ per $100 \mathrm{~g}$, respectively, $P$ $<0.01$ ). No significant difference in either blood $\mathrm{pH}$ or bicarbonate levels were found between $\mathbf{S}$ and $\mathbf{R}$ rats on either the $0.08 \%, 1 \%$, or $8 \%$ salt diets. We conclude that renal acid excretion is augmented in the salt-sensitive Dahl/Rapp rat. Enhanced renal acid excretion may be a marker of increased acid production by cells from subjects with salt-sensitive hypertension. (J. Clin. Invest. 1993. 91:2178-2184.) Key words: saltsensitive hypertension • acid excretion $\bullet$ intracellular $\mathrm{pH} \cdot \mathrm{Na}^{+} /$ $\mathrm{H}^{+}$antiporter $\bullet$ acid base
\end{abstract}

\section{Introduction}

Recent evidence from animal models of spontaneous hypertension and in humans suggests that primary hypertension may be associated with perturbations of acid-base status. We

Portions of this work were presented at the Annual Meeting of the American Federation for Clinical Research, May 1991, and the American Society of Nephrology, November 1991, Washington, DC.

Address correspondence to D. C. Batlle, M. D., Division of Nephrology/Hypertension, Department of Medicine, Northwestern University Medical School, 303 E. Chicago Avenue, Chicago, IL 6061 1-3008. Dr. Batlle is a member of the Feinberg Cardiovascular Research Institute of Northwestern University.

Received for publication 19 October 1992 and in revised form 18 December 1992.

1. Abbreviations used in this paper: BCECF-AM, 2',7'-bis (carboxyethyl)-5(6)-carboxyfluorescein acetomethyl ester; $\mathrm{pH}_{\mathrm{i}}$, intracellular $\mathrm{pH}$; R, salt-resistant; S, salt sensitive; SHR, spontaneous hypertensive rat.

The Journal of Clinical Investigation, Inc.

Volume 91, May 1993, 2178-2184 have shown that intracellular $\mathrm{pH}\left(\mathrm{pH}_{\mathrm{i}}\right)^{1}$ in lymphocytes from the spontaneous hypertensive rat (SHR) is lower than that of the normotensive Wistar-Kyoto rat (WKY) $(1,2)$. Other investigators have reported mild metabolic acidosis in the SHR and Milan hypertensive rat (3), and in the stroke-prone SHR (4) as compared to their respective normotensive controls. Lower extracellular $\mathrm{pH}$ and bicarbonate levels have recently also been described in salt-sensitive compared to salt-resistant humans (5). Enhanced activity of the $\mathrm{Na}^{+} / \mathrm{H}^{+}$antiporter, a major mechanism of cell defense against cellular acidification, has been reported in lymphocytes and platelets from the SHR (6), and in the renal brush border membrane of SHR (7) and Milan hypertensive rats (8). Others have shown enhanced responsiveness of the renal proximal $\mathrm{Na}^{+} / \mathrm{H}^{+}$antiporter of SHR rats to certain hormonal stimulations (9). Based on our findings that lymphocytic $\mathrm{pH}_{\mathrm{i}}$ was reduced in the SHR, and that the kinetic properties of the $\mathrm{Na}^{+} / \mathrm{H}^{+}$antiporter were virtually identical between lymphocytes from SHR and WKY rats, we have advanced the hypothesis that overactivity of this antiporter is not a primary event, but rather reflects intracellular acidosis in the SHR model of hypertension $(1,2)$.

The Dahl/Rapp rat, a widely used model of salt-sensitive genetic hypertension, has not been studied with respect to acidbase status. This model is particularly useful to study genetic hypertension because the inbred salt-sensitive $(S)$ and salt-resistant $(R)$ rats are genetically identical at $80 \%$ of the defined loci, whereas SHR and WKY rats have a more heterogenous background $(10)$. We thus decided to measure $\mathrm{pH}_{\mathrm{i}}$ in this model of hypertension, reasoning that an abnormality of intracellular acid-base homeostasis should have an impact on renal acid excretion. Accordingly, we studied parameters of intracellular and extracellular acid base status, as well as renal acid excretion in the Dahl/Rapp salt-sensitive rat as compared to its genetically salt-resistant control. These studies were performed in $\mathrm{S}$ rats made hypertensive by exposure to a high salt diet, and in $\mathrm{S}$ rats in which the development of hypertension had been prevented by severe salt restriction. To rule out differences in food intake as a confounding factor, additional studies were conducted in $\mathrm{S}$ and $\mathrm{R}$ rats under strict pair-feeding conditions, and while on a more physiological level of salt intake (1\%).

\section{Methods}

\section{Animals and diets}

3-wk-old male Dahl/ Rapp S and R rats obtained from Harlan Sprague Dawley (Indianapolis, IN) immediately after weaning, were allowed to acclimatize for $1-2 d$ to our animal facilities under controlled temperature and humidity conditions while given a normal rat chow ( $1 \%$ salt, No. 90382; Teklad Premier Laboratory Diets, Madison, WI). S and R rats were then placed on either a very high salt diet ( $8 \%$ salt, No. 82050; Teklad $)$ or very low salt diet $(0.08 \%$ salt, No. 85292 ; Teklad $)$ for $3 \mathrm{wk}$. The low salt diet was a direct modification of the high salt diet with the added salt omitted and the corn adjusted accordingly. For these studies, intake of food and water was allowed ad lib.

In additional studies, 3-4-wk-old $\mathrm{S}$ and $\mathrm{R}$ rats were placed on a 
normal rat diet ( $1 \%$ salt, No. 90382 ; Teklad) for a total of $5 \mathrm{wk}$. During the last $11 \mathrm{~d}$ on this diet, $\mathrm{S}$ and $\mathrm{R}$ animals were strictly pair-fed while housed in individual metabolic cages. Body weight and food intake were monitored daily whereas systolic blood pressure was measured every $3-4 \mathrm{~d}$ by the tail-cuff method (1).

\section{Study protocols}

Intracellular $\mathrm{pH}$. This protocol was designed to evaluate the $\mathrm{pH}_{\mathrm{i}}$ of freshly obtained thymic lymphocytes from $\mathrm{S}$ and $\mathrm{R}$ rats. After 3 wk on either a high ( $8 \%$ ) or a low salt diet $(0.08 \%)$, the rats were weighed and anesthetized with $10 \mathrm{mg} / 100 \mathrm{~g}$ body wt ethyl, 1 -methylpropylthiobarbiturate (Inactin; BYK Gulden, Hamburg, Germany) given intraperitoneally. The chest cavity of the rat was opened, and the thymus removed with fine forceps and cleaned of blood vessels. Intracellular $\mathrm{pH}$ was measured in freshly prepared suspensions of thymic lymphocytes as described previously (1). In brief, contaminating blood was removed from the thymus preparation by rinsing in RPMI 1640 . The thymus was then minced and pipetted vigorously with a syringe several times. Large cell aggregates and connective tissue were removed by passing through four layers of surgical gauze. The resulting suspension of lymphocytes, free of contamination by red blood cells, was centrifuged at $150 \mathrm{~g}$ for $5 \mathrm{~min}$. The cell pellet was then washed and resuspended in RPMI.

The pH-sensitive fluorescent probe 2',7'-bis(carboxyethyl)-5(6)carboxyfluorescein acetomethyl ester (BCECF-AM) was used to determine $\mathrm{pH}_{\mathrm{i}}$ as described previously (1). In brief, cell suspensions (2-2.5 $\times 10^{7}$ cells $\left./ \mathrm{ml}\right)$ were incubated with BCECF-AM $(3 \mu \mathrm{g} / \mathrm{ml})$ for $30 \mathrm{~min}$ at $37^{\circ} \mathrm{C}$. The dye-loaded cells were kept under constant magnetic stirring in a thermostatically controlled cuvette $\left(37^{\circ} \mathrm{C}\right)$ in a spectrofluorometer ( LS-5; Perkin-Elmer Cetus Instruments, Norwalk, CT). Fluorescence measurements were taken at excitation wavelengths of 500 and $440 \mathrm{~nm}$ with an emission wavelength of $520 \mathrm{~nm}$. Steady-state $\mathrm{pH}_{\mathrm{i}}$ was taken after the first $5 \mathrm{~min}$ of stable BCECF-AM fluorescence recording. $\mathrm{pH}_{\mathrm{i}}$ was calculated from the ratio of 500:440 BCECF-AM fluorescence signals using the slope and the intercept of a calibration curve generated for each experiment.

The standard buffer solution ( $\mathrm{pH} 7.40$ ) contained $(\mathrm{mM}): \mathrm{NaCl}$ $135, \mathrm{KCl} 3.5, \mathrm{CaCl}_{2} 1.25, \mathrm{KH}_{2} \mathrm{PO}_{4} 1.2, \mathrm{~N}$-2-hydroxyethylpiperazine$N^{\prime}$-2-ethanesulfonic acid (Hepes) 5.0, dextrose 3.0. When a bicarbonate buffer solution was used, $25 \mathrm{mM} \mathrm{NaHCO}$ was added and $\mathrm{NaCl}$ was reduced to $115 \mathrm{mM}$. The solution ( $\mathrm{pH} 7.40$ ) was equilibrated with $5 \%$ $\mathrm{CO}_{2}$ and $95 \% \mathrm{O}_{2}$ for $30 \mathrm{~min}$ before use. Calibration was carried out in $\mathrm{KCl}$ buffer containing $120 \mathrm{mM} \mathrm{K}^{+}$using the nigericin technique (1). All calibration curves had a correlation coefficient of 0.99 or higher.

Extracellular acid-base status and renal acid excretion. In a separate group of $\mathrm{S}$ and $\mathrm{R}$ rats, which had been on either a high ( $8 \%$ ) or a low $(0.08 \%)$ salt diet for $3 \mathrm{wk}$ as in the previous group, we evaluated renal acid excretion and extracellular acid-base status. For the collection of urine for evaluation of urinary acid and electrolyte excretion, individual animals were placed in individual metabolic cages with free access to their respective diets and tap water. Two consecutive 24-h urine samples were collected in flasks containing mineral oil and thymol preservative, located below each cage. After this, body weight and blood pressure were measured daily in each animal.

This metabolic study was followed by arterial cannulation for the examination of the systemic acid-base status of $S$ and $R$ rats. For this, the rats were anesthetized with methohexital (Brevital; Eli Lilly and Co., Indianapolis, IN ) given intraperitoneally $(0.5 \mathrm{mg} / 100 \mathrm{~g}$ body wt $)$. One carotid artery and one jugular vein were then cannulated. Under light anesthesia, an arterial blood sample was drawn for the measurement of blood $\mathrm{pH}, \mathrm{PCO}_{2}$, and bicarbonate levels. Immediately after this, the rats were further anesthesized with ethyl, 1-methylpropylthiobarbiturate (Inactin; BYK Gulden), $10 \mathrm{mg} / 100 \mathrm{~g}$ body wt i.p., and placed on a servocontrolled heated table. After tracheostomy the rats were connected to a rodent respirator (model 680; Harvard Apparatus Co., Inc., S. Natick, MA), and were ventilated at a rate adjusted to sustain a blood $\mathrm{PCO}_{2}$ of $\sim 40 \mathrm{mmHg}$. This protocol was also used to measure GFR. The bladder was catheterized through an abdominal incision, and $\left[{ }^{125} \mathrm{I}\right]$ iothalamate diluted in saline $(0.75 \mu \mathrm{Ci} / \mathrm{ml} ; 0.024$ $\mathrm{ml} / \mathrm{min}$ ) was infused i.v. An equilibration period of $60 \mathrm{~min}$ was allowed before any collection was started. Urine was then collected under mineral oil over two 60 -min periods. In the middle of each period, arterial blood samples were drawn for the measurement of $\mathrm{pH}, \mathrm{PCO}_{2}$, electrolytes, and $\left[{ }^{125} \mathrm{I}\right]$ iothalamate as previously described (11).

Extracellular acid-base status and renal acid excretion in pair-fed $S$ and $R$ rats on a $1 \%$ salt diet. In this group of animals we used a $1 \%$ salt diet to evaluate acid excretion under conditions of a more physiological salt intake. At the time of study these animals were $\sim 2$ wk older than the animals in the previous two groups ( 8 and $0.08 \%$ salt diets). To rule out differences in food intake as a possible factor accounting for differences in renal acid excretion between $S$ and $R$ rats, the animals in this series were strictly pair-fed. Following an evaluation under ad lib food intake for $4 \mathrm{~d}$, pair-feeding was started and maintained for 11 consecutive days. Free intake of water was allowed throughout the study. Food and water intake were measured and, for the assessment of renal acid and electrolyte excretion, 24-h urine samples were collected daily. At the termination of this study, these animals were prepared for surgery and arterial cannulation for evaluation of systemic acid-base status, and GFR measurements as described above.

\section{Analytical methods}

The $\mathrm{pH}$ of the urine samples was measured immediately after collection on a Radiometer system (Radiometer America Inc., Westlake, $\mathrm{OH})$. Titratable acidity was calculated from the amount of $0.1 \mathrm{NaOH}$ used to titrate a $1-\mathrm{ml}$ sample $(0.1 \mathrm{ml}$ urine plus $0.9 \mathrm{ml}$ distilled water $)$ up to a pH of 7.4 (11). Ammonium was measured by a formalin titrimetric method (11). Blood $\mathrm{pH}$ and $\mathrm{PCO}_{2}$ were measured immediately after collection from the carotid artery on a Radiometer system. Blood bicarbonate concentration was calculated from the $\mathrm{pH}$ and $\mathrm{PCO}_{2}$ using the Henderson-Hasselbalch equation. Since bicarbonate concentration at the urinary $\mathrm{pH}$ range observed $(\sim 6.4)$ is small, we ignored urinary bicarbonate for the calculation of net acid excretion which was estimated from the sum of titratable acidity and ammonium excretion. Sodium and potassium were measured using a flame photometer. Chloride was measured by colorimetric titration with potentiometric endpoint detection.

\section{Statistical analysis}

To determine if there were significant differences between $S$ and $R$ rats in a given variable, statistical analysis was performed using the Student's $t$ test (unpaired data analysis). For repeated measures over time of a given variable we used two-way ANOVA. Differences were considered significant if $P<0.05$. Data are expressed as means \pm SEM.

\section{Results}

Intracellular $\mathrm{pH}$ (Table I). In rats on a high salt diet, the $\mathrm{pH}_{\mathrm{i}}$ of thymic lymphocytes was significantly lower in $\mathrm{S}$ than in $\mathrm{R}$ rats. This difference in $\mathrm{pH}_{\mathrm{i}}$ was observed both in the presence and absence of $\mathrm{HCO}_{3} / \mathrm{CO}_{2}$ in the media. In rats on a low salt diet, mean $\mathrm{pH}_{\mathrm{i}}$ was also lower in the $\mathrm{S}$ than in $\mathrm{R}$ rats, but the difference did not reach statistical significance.

Severe dietary salt deprivation was associated with reduced $\mathrm{pH}_{\mathrm{i}}$ in both $\mathrm{S}$ and $\mathrm{R}$ rats as compared to their respective counterparts placed on a high salt diet. This difference, however, achieved statistical significance only when $\mathrm{pH}_{\mathrm{i}}$ was measured in the presence of $\mathrm{HCO}_{3} / \mathrm{CO}_{2}$ in the media (Table I).

As expected, systolic blood pressure was higher in $\mathrm{S}$ rats on the high salt diet than in $\mathrm{S}$ rats on the low salt diet. In contrast, in $\mathbf{R}$ rats the high salt diet had no significant effect on blood pressure as compared to the low salt diet (Table I). This is in keeping with the well known resistance of $R$ rats to the development of salt-sensitive hypertension (12). Under the low salt diet, both $\mathrm{S}$ and $\mathrm{R}$ young rats displayed stunted growth as 
Table I. Blood Pressure, Body Weight, and Intracellular pH in Dahl/Rapp Salt-resistant and Salt-sensitive Rats

\begin{tabular}{|c|c|c|c|c|c|c|}
\hline \multirow[b]{2}{*}{ Variables } & \multicolumn{3}{|c|}{ Low salt diet } & \multicolumn{3}{|c|}{ High salt diet } \\
\hline & $\begin{array}{l}\text { Salt resistant } \\
\text { (R) }\end{array}$ & $P$ value* & $\begin{array}{l}\text { Salt sensitive } \\
\text { (S) }\end{array}$ & $\begin{array}{l}\text { Salt resistant } \\
\text { (R) }\end{array}$ & $P$ value $^{\ddagger}$ & $\begin{array}{l}\text { Salt sensitive } \\
\text { (S) }\end{array}$ \\
\hline Blood pressure (mmHg) & $95 \pm 9.0(13)$ & NS & $103 \pm 10(12)$ & $99.4 \pm 4.0(18)$ & $<0.001$ & $174 \pm 7.0(16)$ \\
\hline Body weight (g) & $108 \pm 7.0(13)$ & NS & $105 \pm 11(12)$ & $223 \pm 17(18)^{\S}$ & NS & $193 \pm 14(16)^{8}$ \\
\hline $\mathrm{pH}_{\mathrm{i}}\left(\mathrm{HCO}_{3} / \mathrm{CO}_{2}\right.$ buffer $)$ & $7.21 \pm 0.05(13)$ & NS & $7.16 \pm 0.05(12)$ & $7.38 \pm 0.02(12)^{\S}$ & $<0.05$ & $7.32 \pm 0.02(8)^{8}$ \\
\hline $\mathrm{pH}_{\mathrm{i}}$ (Hepes buffer) & $7.22 \pm 0.04(13)$ & NS & $7.15 \pm 0.05(12)$ & $7.27 \pm 0.02(18)$ & $<0.05$ & $7.18 \pm 0.04(16)$ \\
\hline
\end{tabular}

The numbers in parentheses denotes number of rats studied.

* $P$ values between $\mathrm{S}$ and $\mathrm{R}$ rats on a low salt diet.

$\ddagger P$ values between $\mathrm{S}$ and $\mathrm{R}$ rats on a high salt diet.

${ }^{\S}$ Statistically significant difference $(P<0.05)$ between high salt and low salt groups ( $\mathrm{R}$ vs $\mathrm{R}$ and $\mathrm{S}$ vs $\mathrm{S}$, respectively). Unless indicated by the asterisk no significant differences were found between $R$ and $R$ or between $S$ and $S$.

evidenced by a marked impairment of body weight gain as compared to rats of the same age placed on the high salt diet. Stunted growth has been previously demonstrated in Dahl rats subjected to extreme dietary salt deprivation (12).

Extracellular acid-base status and renal acid excretion ( $\mathrm{Ta}$ ble II). No significant differences in blood $\mathrm{pH}$ and blood bicarbonate were found between anesthetized $S$ and $R$ rats on either the high or low salt diets (Table II). When measured during spontaneous respiration under light anesthesia, blood $\mathrm{pH}$ and blood $\mathrm{PCO}_{2}$ were also not significantly different between $\mathrm{S}$ and $R$ rats on either a low or a high salt diet (data not shown).

Blood $\mathrm{pH}$ and bicarbonate levels in both $\mathrm{S}$ and $\mathrm{R}$ rats placed on the low salt diet $(0.08 \%)$ were significantly lower than in their respective counterparts on the high salt diet $(8 \%)$. The finding of metabolic acidosis during severe salt deprivation was in keeping with the finding of lower $\mathrm{pH}_{\mathrm{i}}$ in $\mathrm{S}$ and $\mathrm{R}$ rats on a low salt diet as compared to those on a high salt diet (see $\mathrm{pH}_{\mathrm{i}}$ data $\left(\mathrm{HCO}_{3} / \mathrm{CO}_{2}\right)$ in Table $\left.\mathrm{I}\right)$.

Under the high salt diet, $\mathrm{S}$ rats had markedly higher rates of acid excretion than those of $R$ rats, and this difference was due to higher rates of both ammonium and titratable acid excretion (Table II). The urinary $\mathrm{pH}$ was slightly but significantly lower in $\mathrm{S}$ than in $\mathrm{R}$ rats. The difference in urinary $\mathrm{pH}$, however, was too small to account for the larger difference in titratable acid suggesting that the excretion of urinary buffers, namely phosphate, was higher in $S$ than in $R$ rats. GFR was not significantly different between the two strains.

Under the very low salt diet, $S$ rats also excreted more ammonium and titratable acidity than $R$ rats. Although the difference in either of these two parameters did not achieve statistical significance, net acid excretion was significantly higher in $\mathrm{S}$ than in $\mathrm{R}$ rats (Table II). There were no significant differences

Table II. Acid-base Status, Plasma Electrolytes, and Renal Parameters in Dahl Salt-resistant and Salt-sensitive Rats

\begin{tabular}{|c|c|c|c|c|c|c|}
\hline \multirow[b]{2}{*}{ Variables } & \multicolumn{3}{|c|}{ Low salt diet } & \multicolumn{3}{|c|}{ High salt diet } \\
\hline & Salt resistant & $P$ value* & Salt sensitive & Salt resistant & $P$ value ${ }^{\ddagger}$ & Salt sensitive \\
\hline & $n=9$ & & $n=9$ & $n=10$ & & $n=10$ \\
\hline Blood pH & $7.308 \pm 0.017$ & NS & $7.248 \pm 0.035$ & $7.379 \pm 0.008^{\S}$ & NS & $7.372 \pm 0.011^{8}$ \\
\hline Blood $\mathrm{HCO}_{3}^{-}$(mEq/liter) & $19.1 \pm 1.1$ & NS & $18.0 \pm 1.3$ & $23.9 \pm 0.4^{\S}$ & NS & $23.3 \pm 1.1^{8}$ \\
\hline Blood $\mathrm{PCO}_{2}(\mathrm{mmHg})$ & $40.4 \pm 1.4$ & NS & $41.2 \pm 1.0$ & $41.3 \pm 0.2$ & NS & $41.6 \pm 1.2$ \\
\hline Plasma Na ${ }^{+}$(mEq/liter) & $146.3 \pm 2.8$ & NS & $144.3 \pm 1.1$ & $146.9 \pm 0.9$ & NS & $149.4 \pm 1.3^{\S}$ \\
\hline Plasma $\mathrm{Cl}^{-}$(mEq/liter) & $121.0 \pm 3.0$ & NS & $119.4 \pm 2.6$ & $113.6 \pm 3.4$ & NS & $116.5 \pm 3.8$ \\
\hline Plasma K ${ }^{+}$(mEq/liter) & $4.7 \pm 0.1$ & NS & $4.9 \pm 0.3$ & $3.7 \pm 0.1^{\S}$ & NS & $3.6 \pm 0.2^{\S}$ \\
\hline $\mathrm{GFR}(\mathrm{ml} / \mathrm{min}$ per $100 \mathrm{~g})$ & $1.08 \pm 0.37$ & NS & $1.03 \pm 0.27$ & $0.97 \pm 0.17$ & NS & $0.88 \pm 0.19$ \\
\hline Urine $\mathrm{pH}$ & $6.35 \pm 0.14$ & NS & $6.29 \pm 0.15$ & $6.59 \pm 0.07$ & $<0.05$ & $6.30 \pm 0.12$ \\
\hline $\mathrm{U}_{\mathrm{TA}} \mathrm{V}(\mu \mathrm{Eq} / 24$ per $\mathrm{h} 100 \mathrm{~g})$ & $184 \pm 39$ & NS & $247 \pm 44$ & $299 \pm 43^{\S}$ & $<0.001$ & $706 \pm 67^{8}$ \\
\hline $\mathrm{U}_{\mathrm{NH} \downarrow} \mathrm{V}(\mu \mathrm{Eq} / 24 \mathrm{~h}$ per $100 \mathrm{~g})$ & $214 \pm 45$ & NS & $316 \pm 41$ & $718 \pm 56^{\S}$ & $<0.005$ & $1071 \pm 77^{\S}$ \\
\hline $\mathrm{U}_{\mathrm{NAE}} \mathrm{V}(\mu \mathrm{Eq} / 24 \mathrm{~h}$ per $100 \mathrm{~g})$ & $398 \pm 59$ & $<0.05$ & $563 \pm 67$ & $1017 \pm 73^{\S}$ & $<0.001$ & $1777 \pm 111^{8}$ \\
\hline 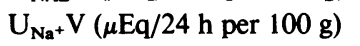 & $<0.01$ & - & $<0.01$ & $6289 \pm 119^{8}$ & $<0.01$ & $7305 \pm 242^{\S}$ \\
\hline $\mathrm{U}_{\mathrm{Vol}}(\mathrm{ml} / 24 \mathrm{~h}$ per $100 \mathrm{~g})$ & $4.2 \pm 1.0$ & NS & $6.5 \pm 1.6$ & $25.2 \pm 0.8^{8}$ & $<0.001$ & $35.4 \pm 2.1^{\S}$ \\
\hline
\end{tabular}

* $P$ values between $\mathrm{S}$ and $\mathrm{R}$ rats on a low salt diet.

${ }^{\ddagger} P$ values between $\mathrm{S}$ and $\mathrm{R}$ rats on a high salt diet.

${ }^{\S}$ Statistically significant difference $(P<0.01)$ between high salt and low salt groups ( $R$ vs. $R$ and $S$ vs. $\left.S\right)$. Unless indicated by the asterisk statistically significant differences were not found.

TA, titratable acidity; NAE, net acid excretion. 
in GFR between $S$ and $R$ rats subjected to severe salt deprivation. Sodium excretion was virtually zero in both $S$ and $R$ rat strains.

Excretion of titratable acidity, ammonium, and net acid were markedly lower in both $\mathrm{S}$ and $\mathrm{R}$ rats under the low salt diet than in their respective counterparts on the high salt diet. The lower rates of acid excretion of animals on a low salt diet were noted despite the fact that systemic acidosis had developed in these animals.

Extracellular acid-base status and renal acid excretion in pair-fed $S$ and $R$ rats on a $1 \%$ salt diet (Table III and Figs. 1 and 2). In this group food intake was monitored daily throughout the metabolic study. During pair-feeding, food intake (by design ) and the gain in body weight were similar in $S$ and $R$ rats (Fig. 1). Throughout the period of pair-feeding blood pressure was higher in $\mathbf{S}$ than in $\mathbf{R}$ rats (data not shown). Blood pressure data at the end of the pair-feeding protocol are given in Table III.

Both before and during pair-feeding, urinary excretion of titratable acid, ammonium and net acid was higher in $\mathrm{S}$ than in $R$ rats (Figs. 1 and 2). Arterial acid-base parameters, evaluated after the completion of the metabolic study in anesthetized rats, revealed no significant difference in either blood $\mathrm{pH}$ or blood bicarbonate between $\mathrm{S}$ and $\mathrm{R}$ rats (Table III). Plasma levels of sodium, chloride, and potassium, as well as GFR were also not significantly different between the two groups. Plasma potassium levels were slightly reduced in both $S$ and $R$ rats. GFR was not significantly different between the two strains.

Fig. 3 summarizes the data on net acid excretion, corrected per $100 \mathrm{~g}$ body wt, of $\mathrm{S}$ and $\mathrm{R}$ rats placed on the three different levels of salt intake $(0.08,1$, and $8 \%$ salt diets). The extreme level of salt intake ( $8 \%)$, usually used to produce hypertension in the $S$ rat (12), is clearly supraphysiological, and is also problematic because acid excretion is influenced by salt intake (13, 14). It is, thus, important to point out that we were able to

Table III. Data from Dahl Salt-resistant and Salt-sensitive Rats on a $1 \%$ Salt Diet

\begin{tabular}{|c|c|c|c|}
\hline \multirow[b]{2}{*}{ Variables } & \multicolumn{3}{|c|}{$1 \%$ Salt diet } \\
\hline & Salt resistant & $P$ value & Salt sensitive \\
\hline & $n=6$ & & $n=6$ \\
\hline Blood pressure $(\mathrm{mmHg})$ & $94.1 \pm 8.0$ & $<0.001$ & $151.0 \pm 4.4$ \\
\hline Body weight (g) & $302.1 \pm 7.6$ & NS & $302.0 \pm 5.3$ \\
\hline Blood pH & $7.404 \pm 0.012$ & NS & $7.366 \pm 0.026$ \\
\hline Blood $\mathrm{HCO}_{3}{ }^{-}(\mathrm{mEq} /$ liter $)$ & $23.0 \pm 0.8$ & NS & $22.0 \pm 1.9$ \\
\hline Blood $\mathrm{PCO}_{2}(\mathrm{mmHg})$ & $37.9 \pm 0.9$ & NS & $39.2 \pm 1.6$ \\
\hline Plasma Na ${ }^{+}(\mathrm{mEq} /$ liter $)$ & $145.3 \pm 3.5$ & NS & $140.7 \pm 4.1$ \\
\hline Plasma Cl${ }^{-}$(mEq/liter) & $112.0 \pm 1.7$ & NS & $111.0 \pm 4.4$ \\
\hline Plasma K ${ }^{+}$(mEq/liter) & $3.1 \pm 0.1$ & NS & $3.2 \pm 0.1$ \\
\hline GFR $(\mathrm{ml} / \mathrm{min}$ per $100 \mathrm{~g})$ & $0.80 \pm 0.01$ & NS & $0.91 \pm 0.10$ \\
\hline Urine $\mathrm{pH}$ & $6.49 \pm 0.03$ & NS & $6.41 \pm 0.03$ \\
\hline $\mathrm{U}_{\mathrm{TA}} \mathrm{V}(\mu \mathrm{Eq} / 24$ h per $100 \mathrm{~g})$ & $184 \pm 13$ & $<0.001$ & $308 \pm 20$ \\
\hline $\mathrm{U}_{\mathrm{NH}^{+}} \mathrm{V}(\mu \mathrm{Eq} / 24 \mathrm{~h}$ per $100 \mathrm{~g})$ & $151 \pm 9$ & $<0.001$ & $278 \pm 16$ \\
\hline $\mathrm{U}_{\mathrm{NAE}} \mathrm{V}(\mu \mathrm{Eq} / 24 \mathrm{~h}$ per $100 \mathrm{~g})$ & $328 \pm 21$ & $<0.001$ & $563 \pm 29$ \\
\hline $\mathrm{U}_{\mathrm{Na}^{+}}+\mathrm{V}(\mu \mathrm{Eq} / 24 \mathrm{~h}$ per $100 \mathrm{~g})$ & $680 \pm 50$ & $<0.01$ & $979 \pm 55$ \\
\hline $\mathrm{U}_{\mathrm{Vol}}(\mathrm{ml} / 24 \mathrm{~h}$ per $100 \mathrm{~g})$ & $3.2 \pm 0.3$ & $<0.001$ & $5.5 \pm 0.3$ \\
\hline
\end{tabular}

TA, titratable acidity, NAE, net acid excretion.

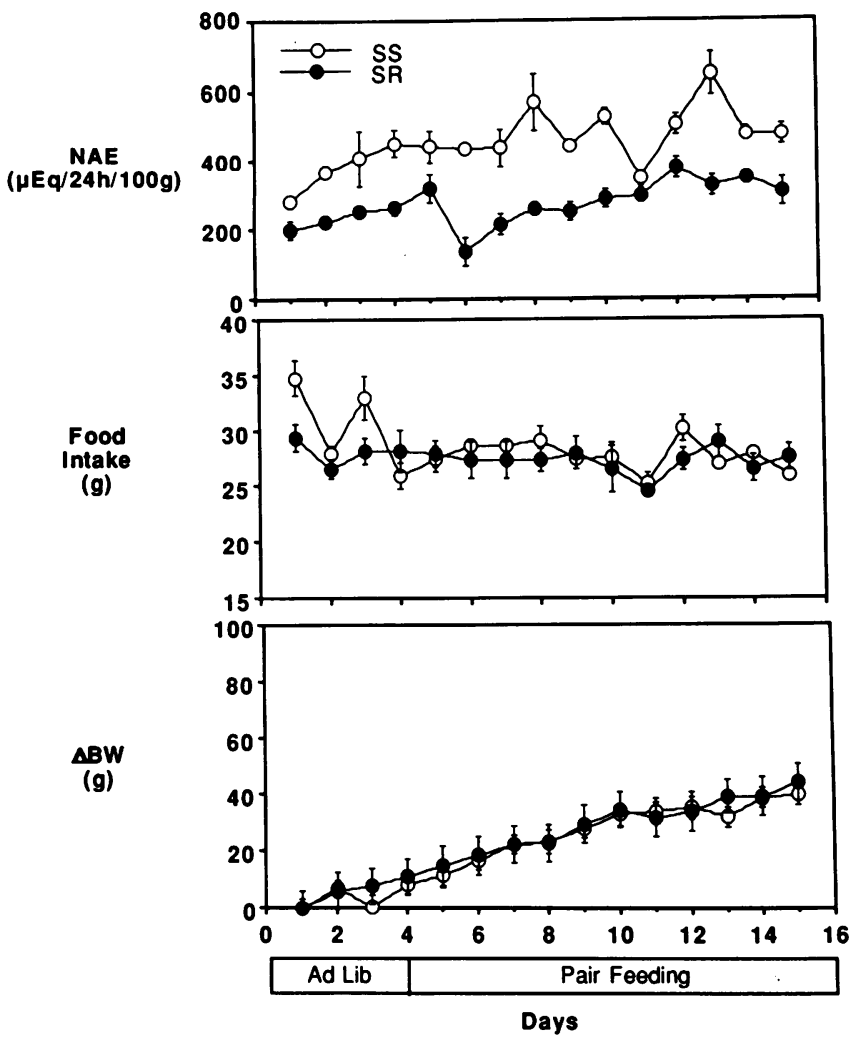

Figure 1. Depicts daily net acid excretion (NAE) ( upper panel), daily food intake (middle panel), and daily total body weight gain ( $D B W$ )

(lower panel) in salt-sensitive (SS) and salt-resistant (SR) Dahl/Rapp rats while on a $1 \%$ salt diet. Net acid excretion was significantly higher in $\mathrm{S}$ than in $\mathrm{R}$ rats throughout the study period $(P<0.001$ by twoway ANOVA).

show that increased net acid excretion was also present in $\mathrm{S}$ rats fed a diet containing more physiological amounts of salt (1\%). Body weight in $\mathrm{S}$ and $\mathrm{R}$ rats placed on a normal salt diet (1\%), was higher than that of animals on the very high salt diet (8\%) likely reflecting their older age ( $9 \mathrm{vs} 7 \mathrm{wk}$ of age). This difference in age (about $2 \mathrm{wk}$ ) between these groups allowed the $S$ rats to develop overt hypertension while on a normal salt intake. This level of salt intake is sufficient to produce a marked rise in blood pressure in the $\mathrm{S}$ rats, although, it takes longer for severe hypertension to develop on this level of salt intake than on the extremely high salt diet used by many investigators ( 12 , 15 ). Thus, with the data available to us, the issue of intrinsic differences vs differences secondary to high blood pressure is best addressed from the data of $S$ and $R$ animals on a very low $\mathrm{NaCl}$ diet. Under this condition blood pressure was not different between $S$ and $R$ rats and yet a small but significant difference in net acid excretion was already apparent (see Fig. 3).

\section{Discussion}

This study describes a previously unrecognized perturbation of acid-base status in rats genetically predisposed to the development of hypertension. When compared to their salt-resistant counterparts, hypertensive salt-sensitive rats placed on either a normal rat chow ( $1 \%$ salt ) or extremely high salt diet $(8 \%)$ had a markedly elevated rate of renal acid excretion. A similar alteration (i.e., higher acid excretion in $S$ than $R$ rats) was also 


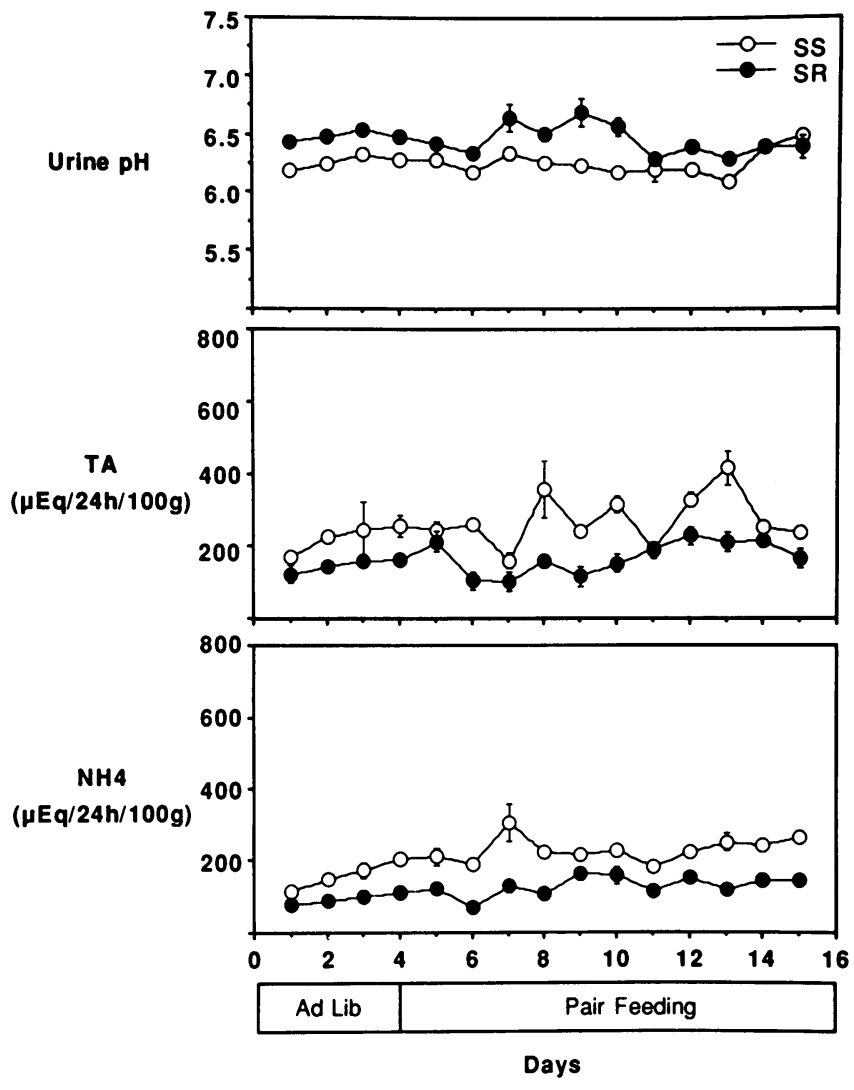

Figure 2. Depicts daily urine $\mathrm{pH}$ ( upper panel), daily titratable acidity ( $T A$ ) (middle panel), and daily ammonium excretion ( $\mathrm{NH} 4$ ) in saltsensitive $(S S)$ and salt-resistant $(S R)$ Dahl/Rapp rats while on a $1 \%$ salt diet. By two-way ANOVA, both titratable acid excretion and ammonium excretion were higher in SS than in SR rats $(P<0.005)$ while urine $\mathrm{pH}$ was lower in SS than in SR rats $(P<0.001)$.

observed when the development of hypertension in $\mathrm{S}$ rats was prevented by extreme dietary salt deprivation (Fig. 3).

We interpret our finding of enhanced renal acid excretion in $\mathrm{S}$ rats as being secondary to increased metabolic acid production. This is suggested by our finding of decreased $\mathrm{pH}_{\mathrm{i}}$ in $\mathrm{S}$ as compared to $\mathrm{R}$ rats (Table $\mathrm{I}$ ). In the face of relative intracellular acidosis, addition of acid equivalents into the systemic circulation would result in titration of plasma bicarbonate leading to systemic acidosis. A significant difference in extracellular acid-base status between the $S$ and $R$ rats, however, could not be demonstrated in this study (Tables II and III). It should be noted that in the face of a renal adaptive increase in acid excretion changes in extracellular acid-base parameters could be discrete or even completely lacking. Extracellular buffering mechanisms would also contribute to the prevention of acidemia or to its attenuation in $\mathrm{S}$ rats.

The markedly increased renal acid excretion found in the $S$ rat is, in fact, the expected renal adaptive response to a systemic acid overload. According to our hypothesis, intracellular acidosis and the attendant addition of acid equivalents into the circullation, even when unaccompanied by a detectable extracellular acidosis, would be the signal for the stimulation of renal acid excretion. It should be noted that rats given exogenous acid loads to produce experimental metabolic acidosis may develop only a transient fall in extracellular $\mathrm{pH}$ (16). After 2-3 wk of acid loading the metabolic acidosis subsides because renal compensatory mechanisms, including redistribution of vacuolar $\mathrm{H}^{+}$ATPase towards the apical pole of renal intercalated cells, result in increased renal bicarbonate reclamation and enhanced acid excretion which eventually leads to a correction of the fall in plasma bicarbonate (16). Thus, overt metabolic acidosis does not need to be a feature accompanying chronic acid overproduction for the same reason that exogenous acid administration may not result in sustained metabolic acidosis when full compensation has taken place.

The foregoing observations also suggest that the higher rate of acid excretion found in $\mathrm{S}$ compared to $\mathrm{R}$ rats is not likely to be the result of an intrinsic renal abnormality. If the observed increase in renal acid excretion had been the result of a primary renal abnormality, one would have expected to find an increase in plasma bicarbonate in $\mathrm{S}$ rats, as found in the syndromes of metabolic alkalosis of renal origin (17). Extracellular pH and bicarbonate levels in $\mathrm{S}$ rats, however, did not reveal the presence of metabolic alkalosis. If anything, extracellular $\mathrm{pH}$ tended to be lower in S than in $\mathrm{R}$ rats (Tables II and III). As in previous studies in young Dahl rats (18), GFR was not significantly different between $S$ and $R$ rats, suggesting the higher acid excretion of $S$ rats could also not be ascribed to a higher GFR. Thus, the observed augmentation in acid excretion does not appear to be due to a primary renal abnormality in $\mathrm{S}$ rats. Rather it appears to be the result of a renal adaptation to systemic acid overproduction.

Increased renal acid excretion in the $\mathrm{S}$ rat was not due to increased food intake, as demonstrated by the pair-feeding study. This indicates that differences in protein intake, an important factor influencing the amount of acid excreted, can be excluded as the cause of increased acid excretion in the $\mathrm{S}$ rat. If acid production from food intake is excluded, then a perturbation of cellular metabolism resulting in an increased production of proton equivalents, seems likely in $\mathrm{S}$ rats. The possibility of enhanced losses of potential base in the stools causing systemic acidosis in $\mathrm{S}$ rats needs to be considered as well. While we cannot completely exclude this possibility, we favor the notion of enhanced acid production at the cellular level.

With few exceptions, cells acidify their environments because of acidic products of energy metabolism. Energy metabolism is largely regulated by cellular demand for ATP, which arises from several metabolic processes. In this respect, it is of interest to note that hypertension is associated with various

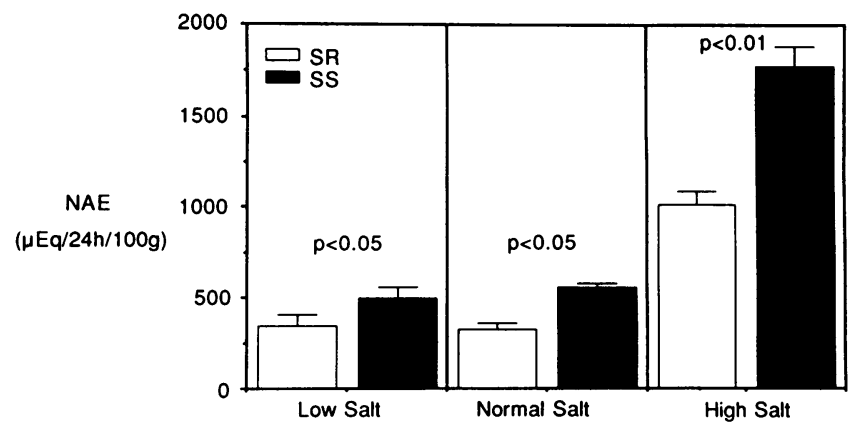

Figure 3. Summary of net acid excretion (NAE) data in salt-sensitive $(S S)$ and salt-resistant $(S R)$ rats obtained at the end of 16-21 d on a low salt diet $(0.08 \%)$, normal salt diet ( $1 \%)$, and high salt diet $(8 \%)$. Significant differences were observed at all levels of salt intake by Student's $t$ test (unpaired data analysis). 
metabolic abnormalities $(19,20)$. Higher oxygen consumption, indicating increased basal metabolic rate, has been described in the SHR model of hypertension (21). Body temperature is also higher in the SHR than in the WKY rat (22). It is of interest to note that when temperature increases up to $37^{\circ} \mathrm{C}$, there is a progressive fall in $\mathrm{pHi}(23)$. We mention this point on purely speculative grounds, because cell temperature was controlled at $37^{\circ} \mathrm{C}$ in the cuvette in which cells were suspended for $\mathrm{pH}_{\mathrm{i}}$ measurements. Moreover, we know of no data pertinent to body temperature or metabolic rate in the Dahl rat. It is possible that the underlying metabolic process that could cause an increase in body temperature in vivo in the SHR, if also present in salt-sensitive Dahl rats, may likewise be responsible for increased cellular acid production. One may also speculate, that increased acid excretion in $S$ rats could be somehow related to the abnormalities in lipid and carbohydrate metabolism resulting from the presence of insulin resistance in this model of salt-sensitive hypertension (24). The hypertriglyceridemia present in the $S$ rats could, by shifting energy production towards fatty acid oxidation (Randle's cycle), leading to the accumulation of acidic metabolites (25). Our finding of intracellular acidosis may be related to the same or to a similar underlying metabolic process which results in cellular acid over production. In this context, enhanced acid excretion by the kidneys may provide a total body marker for enhanced cell metabolism associated with hypertension.

Under extreme dietary salt restriction, extracellular and intracellular $\mathrm{pH}$ were reduced in both $\mathrm{S}$ and $\mathrm{R}$ rats compared to their counterparts on the high salt diets. Despite the marked intracellular acidosis, acid excretion was not higher in these rats than in those on the high salt diets. This likely reflects a limitation in the ability of the kidneys to augment acid excretion under conditions of a profound impairment in sodium delivery to the $\mathrm{H}^{+}$secretory sites in the distal nephron $(13,14)$. In fact, inability to increase acid excretion maximally as a result of such a limitation may have contributed significantly to the development of metabolic acidosis in the rats on the very low salt diet. Even under these seemingly extreme conditions, however, net acid excretion was still higher in $S$ than in $R$ rats (Fig. 3). Thus, a higher rate of acid excretion appears to be a feature of salt-sensitive Dahl/Rapp rats which is present at all levels of salt intake likely reflecting endogenous acid overproduction.

How could our findings of increased renal acid excretion and reduced $\mathrm{pH}_{\mathrm{i}}$ relate to hypertension in the $\mathrm{S}$ rat? One possibility is that intracellular acidosis could stimulate both renal bicarbonate and sodium reabsorption. In response to acid loading or metabolic acidosis $(26,27)$ the activity of the $\mathrm{Na}^{+} / \mathrm{H}^{+}$ exchanger in renal proximal cells increases. Overactivity of this transporter would lead to enhanced $\mathrm{Na}^{+}$reabsorption as well as $\mathrm{H}^{+}$secretion $\left(\mathrm{HCO}_{3}^{-}\right.$reabsorption $)(28,29)$. One can thus envision a situation where increased activity of the $\mathrm{Na}^{+} / \mathrm{H}^{+}$ antiporter, resulting from increased cellular acid production, could play a role in the initiation of hypertension by contributing significantly to renal sodium retention in $\mathrm{S}$ rats. We think the findings of the present study may explain previous observations that provision of sodium as sodium bicarbonate or sodium citrate, unlike sodium chloride, does not increase blood pressure in salt-sensitive individuals (30). These alkalinizing agents could suppress the overactivity of the $\mathrm{Na}^{+} / \mathrm{H}^{+}$antiporter by neutralizing acid overproduced by these salt-sensitive hypertensive individuals. In other words, we propose that in- tracellular acidosis is the stimulus for exaggerated renal sodium retention via $\mathrm{Na}^{+} / \mathrm{H}^{+}$exchange in salt-sensitive individuals, and that such stimulus is removed by provision of alkali. It should be noted that sodium retention in the $S$ rat cannot be easily demonstrated because, as these animals develop accelerated hypertension, $\mathrm{Na}^{+}$excretion increases. In fact, once hypertension has developed, $S$ rats on a physiological salt intake have an $\mathrm{Na}^{+}$excretion higher than that of normotensive $\mathrm{R}$ rats (Table III). This is likely due to the well known phenomenon of pressure natriuresis (31). That $S$ rats do have a reduced ability for $\mathrm{Na}^{+}$excretion is best uncovered when systemic blood pressure in $\mathrm{R}$ rats is increased to the level of $\mathrm{S}$ rats (18). Under this condition, $\mathrm{Na}^{+}$excretion in $\mathrm{S}$ rats is clearly lower than in $\mathrm{R}$ rats.

Another link between acid overproduction and hypertension can be envisioned at the level of cells other than kidney cells where reduced $\mathrm{pH}_{\mathrm{i}}$ would also stimulate $\mathrm{Na}^{+} / \mathrm{H}^{+}$exchange thereby promoting cell $\mathrm{Na}^{+}$influx and intracellular $\mathrm{Na}^{+}$accumulation. This increase in cell $\mathrm{Na}^{+}$could also contribute to an increase in intracellular $\mathrm{Ca}^{2+}$ via a plasma membrane $\mathrm{Na}^{+} / \mathrm{Ca}^{2+}$ exchanger. There is recent data from our laboratory showing that under a high salt diet, thymic lymphocytes from Dahl/Rapp $S$ rats but not $R$ rats, display an increase in free cytosolic $\mathrm{Ca}^{2+}$ (32). Thus, it seems likely that Dahl/Rapp S rats have some of the same alterations in ionic cell composition described in thymic lymphocytes from the SHR model, which include reduced intracellular $\mathrm{pH}$ (1), elevated free cytosolic $\mathrm{Ca}^{2+}(33)$ and elevated free cytosolic $\mathrm{Na}^{+}(34)$. Intracellular acidosis may be part of a generalized alteration in cellular ionic composition prevailing in some forms of genetic hypertension which may be expressed at the whole animal level by enhanced renal acid excretion.

The notion of acid overproduction would be in line with our earlier suggestion, that increased activity of the $\mathrm{Na}^{+} / \mathrm{H}^{+}$ antiporter in hypertension is not a primary event, but rather, a physiological response to intracellular acidosis $(1,2)$. In this respect we wish to note that in platelets and in cultured vascular smooth muscle cells from hypertensive models overactivity of the $\mathrm{Na}^{+} / \mathrm{H}^{+}$antiporter has been described in association with a normal (35) or a high $\mathrm{pH}_{\mathrm{i}}(36)$. These seemingly contradictory findings can be explained, in our opinion, on the basis of in vitro platelet hyperreactivity which has been described in platelets from hypertensive subjects (37) or stimulation of the antiporter during enhanced growth in culture, a feature of vascular smooth muscle cells from the $\operatorname{SHR}(36,38)$. Overactivity of the antiporter in these cell models may result from protein kinase $\mathrm{C}$ activation (39). We think that unstimulated lymphocytes best portray the cellular acid-base environment prevailing in vivo in the whole animal. In freshly isolated thymic lymphocytes $\mathrm{pH}_{\mathrm{i}}$ can be measured with minimal disruption of cellular structures and functions. The possibility of cell specific differences in $\mathrm{pH}_{\mathrm{i}}$ between hypertensive and normotensive subjects, however, needs to be considered as well. Differential regulation of the antiporter by acid-feeding has been recently reported by Moe et al. (26). These authors have shown that acid feeding increases $\mathrm{Na}^{+} / \mathrm{H}^{+}$antiporter mRNA levels in renal cells but decreases it in fibroblasts (26).

In summary, our data show that in the Dahl/Rapp model of salt-sensitive hypertension, renal acid excretion is markedly augmented while $\mathrm{pH}_{\mathrm{i}}$ of freshly isolated thymic lymphocytes is reduced. In the face of intracellular acidosis, the finding of increased acid excretion, under conditions of controlled pro- 
tein intake, suggests endogenous acid overproduction. While the endogenous source and mechanism of this acid overproduction is presently not clear, it may well reflect a derangement of cellular metabolism in the salt-sensitive Dahl/Rapp S rat that could contribute to the development of hypertension. Since cellular metabolic activity typically results in acid production our finding of increased renal acid excretion may prove to be a marker of cellular metabolic changes associated with saltsensitive hypertension. Whether enhanced acid excretion is a feature of human salt sensitivity and whether it occurs in types of hypertension other than the salt-sensitive Dahl rat will need to be investigated.

\section{Acknowledgments}

This study was supported, in part, by a Grant-in-Aid from the American Heart Association (Chicago Affiliation) and a Veterans Administration Merit Review (Dr. D. C. Batlle). Dr. A. M. Sharma was supported, in part, by the Department of Medicine, Division of Nephrology, Klinikum Steglitz, Free University of Berlin.

\section{References}

1. Batlle, D. C., A. Saleh, and G. Rombola. 1990. Reduced intracellular pH in lymphocytes from the spontaneously hypertensive rat. Hypertension (Dallas). 15:97-103.

2. Saleh, A. M., and D. C. Batlle. 1990. Kinetic properties of the $\mathrm{Na}^{+} / \mathrm{H}^{+}$ antiporter of lymphocytes from the spontaneously hypertensive rat: role of intracellular pH. J. Clin. Invest. 85:1734-1739.

3. Lucas, P. A., B. Lacour, D. A. McCarron, and T. Drueke. 1987. Disturbance of acid-base balance in the young spontaneously hypertensive rat. Clin. Sci. (Lond.). 73:211-215.

4. Luft, F. C., H. Steinberg, U. Ganten, D. Meyer, K. H. Gless, R. E. Lang, N. S. Fineberg, W. Rascher, T. Unger, and D. Ganten. 1988. Effect of sodium chloride and sodium bicarbonate on blood pressure in stroke-prone spontaneously hypertensive rats. Clin. Sci. (Lond.). 74:577-585.

5. Sharma, A. M., A. Kribben, S. Schattenfroh, C. Cetto, and A. Distler. 1990. Salt sensitivity in humans is associated with abnormal acid-base regulation. $\mathrm{Hy}$ pertension (Dallas). 16:407-413.

6. Feig, P. U., M. A. D'Occhio, and J. W. Boylan. 1987. Lymphocyte membrane sodium-proton exchange in spontaneously hypertensive rats. Hypertension (Dallas). 9:282-288.

7. Morduchowicz, G. A., D. Sheikh Hamad, O. D. Jo, E. P. Nord, D. B. Lee, and $\mathrm{N}$. Yanagawa. 1989. Increased $\mathrm{Na}^{+} / \mathrm{H}^{+}$antiport activity in the renal brush border membrane of SHR. Kidney Int. 36:576-581.

8. Parenti, P., G. M. Hanozet, and G. Bianchi. 1986. Sodium and glucose transport across renal brush border membranes of Milan hypertensive rats. $\mathrm{Hy}$ pertension (Dallas). 8:932-939.

9. Gesek, F. A., and A. C. Schoolwerth. 1991. Hormone responses of proximal $\mathrm{Na}^{+}-\mathrm{H}^{+}$exchanger in spontaneously hypertensive rats. Am. J. Physiol. 261:F526-F536.

10. Lezin, E., L. Simonet, M. Pravenec, and T. W. Kurtz. 1992. Hypertensive strains and normotensive 'control' strains. How closely are they related? Hypertension (Dallas). 19:419-424.

11. Batlle, D. C., M. Downer, C. Gutterman, and N. A. Kurtzman. 1985. Relationship of urinary and blood carbon dioxide tension during hypercapnia in the rat. J. Clin. Invest. 75:1517-1530.

12. Rapp, J. P. 1982. Dahl salt-susceptible and salt-resistant rats. A review. Hypertension (Dallas). 4:753-763.

13. Alpern, R. J., K. D. Stone, and F. C. Rector, Jr. 1991. Renal acidification mechanisms. In The Kidney. B. M. Brenner and F. C. Rector, Jr., editors. W. B. Saunders Co., Philadelphia. 318-379.

14. Batlle, D. C. Hyperchloremic metabolic acidosis. 1989. In The Regulation of Acid-Base Balance. D. W. Seldin and G. Giebisch, editors. Raven Press, Ltd., New York. 319-351.

15. Chen, P. Y., and P. W. Sanders. 1991. L-Arginine abrogates salt-sensitivity hypertension in Dahl/Rapp rats. J. Clin. Invest. 88:1559-1567.

16. Bastani, B., H. Purcell, P. Hemken, D. Trigg, and S. Gluck. 1991. Expres- sion and distribution of renal vacuolar proton-translocating adenosine triphosphatase in response to chronic acid and alkali loads in the rat. J. Clin. Invest. 88:126-136.

17. Jacobson, H. R. 1989. Chloride-resistant metabolic alkalosis. In The Regulation of Acid-base Balance. D. W. Seldin and G. Giebisch, editors. Raven Press, Ltd., New York. 459-482.

18. Green, A. S., Z. Y. Yu, R. J. Roman, and A. W. Cowley, Jr. 1990. Role of blood volume expansion in Dahl rat model of hypertension. Am. J. Physiol. 258:H508-H512.

19. Landsberg, L. 1986. Diet, obesity and hypertension: a hypothesis involving insulin, the sympathetic system and adaptive thermogenesis. $Q$. J. Med. 236:1081-90.

20. Reaven, G. M., and D. B. Hoffman. 1989. Hypertension is a disease of carbohydrate and lipoprotein metabolism. Kidney Int. 87:25-65.

21. Wright, G. L., E. Knecht, D. Badger, S. Samueloff, M. Toraason, and F. Dukes-Dobos. 1978. Oxygen consumption in the spontaneously hypertensive rat. Proc. Soc. Exp. Biol. Med. 159:449-452.

22. Price, J. M., and F. R. Wilmoth. 1990. Elevated body temperature and increased blood vessel sensitivity in spontaneously hypertensive rats. Am. J. Physiol. 258:H946-H953.

23. Graber, M., C. Barry, J. DiPaola, and A. Hasagawa. 1992. Intracellular pH in OK cells. II. Effects of temperature on cell pH. Am. J. Physiol. 262:F723-F730.

24. Reaven, G. M., J. Twersky, and H. Chang. 1991. Abnormalities of carbohydrate and lipid metabolism in Dahl rats. Hypertension (Dallas). 18:630-635.

25. Randle, P. J., A. L. Kerbey, and J. Espinal. 1988. Mechanism decreasing glucose oxidation in diabetes and starvation: role of lipid fuels and hormones. Diabetes Metab. Rev. 4:623-638.

26. Moe, O. W., R. T. Miller, S. Horie, A. Cano, P. A. Preisig, and R. J. Alpern. 1991. Differential regulation of the $\mathrm{Na} / \mathrm{H}$ antiporter by acid in renal epithelial cells and fibroblasts. J. Clin. Invest. 88:1703-1708.

27. Preisig, P. A., and R. J. Alpern. 1988. Chronic metabolic acidosis causes an adaptation in the apical membrane $\mathrm{Na} / \mathrm{H}$ antiporter and basolateral membrane $\left(\mathrm{Na}\left(\mathrm{HCO}_{3}\right)_{3}\right.$ synporter in the rat proximal convoluted tubule. J. Clin. Invest. 82:1445-1453.

28. Tsai, C. J., H. E. Ives, R. J. Alpern, V. J. Yee, D. G. Warnock, and F. C. J. Rector. 1984. Increased $\mathrm{V}_{\max }$ for $\mathrm{Na}^{+} / \mathrm{H}^{+}$antiporter activity in proximal tubule brush border vesicles from rabbits with metabolic acidosis. Am. J. Physiol. 247:F339-F343.

29. Akiba, T., V. K. Rocco, and D. G. Warnock. 1987. Parallel adaptation of the rabbit renal cortical sodium/proton antiporter and sodium/bicarbonate cotransporter in metabolic acidosis and alkalosis. J. Clin. Invest. 80:308-315.

30. Kurtz, T. W., H. A. Albander, and R. C. T. Morris. 1987. "Salt-sensitive" essential hypertension in men. Is the sodium alone, important? N. Engl. J. Med. 317:1043-1048.

31. Guyton, A. C., J. E. Hall, T. G. Coleman, and R. D. Manning, Jr. 1990. The dominant role of the kidneys in the long-term regulation of arterial pressure in normal and hypertensive states. In Hypertension: Pathophysiology, Diagnosis and Management. Vol. 1. J. H. Laragh and B. M. Brenner, editors. 66:10291052.

32. Sharma, A. M., M. I. Sobrero, A. Saleh, and D. C. Batlle. 1991. Free cytosolic calcium $\left(\mathrm{iCa}^{2+}\right)$ in the Dahl rat: effect of salt intake. Am. J. Hypertens. 4:43A.

33. Batlle, D. C., G. Janss, M. LaPointe, J. Llibre, and A. Saleh. 1990. Cytosolic calcium in $\mathrm{T}$ lymphocytes from the spontaneously hypertensive rat. $\mathrm{Am}$. J. Hypertens. 3:343-348.

34. Gutterman, C., L. A. Gomez, and D. C. Batlle. 1992. Free cytosolic sodium in lymphocytes from SHR and WKY rats monitored with the fluorescent dye SBFI. Clin. Res. 40:317A. (Abstr.)

35. Tokudome, G., H. Tomonari, J. P. Gardner, M. Aladjem, B. P. Fine, N. Lasker, M. Gutkin, L. H. Byrd, and A. Aviv. 1990. Variations in the apparent pH set point for activation of platelet $\mathrm{Na} / \mathrm{H}$ antiport. Hypertension (Dallas). 16:180-189.

36. Berk, B. C., G. Vallega, A. J. Muslin, H. M. Gordon, M. Canessa, and R. W. Alexander. 1989. Spontaneously hypertensive rat vascular smooth muscle cells in culture exhibit increased growth and $\mathrm{Na} / \mathrm{H}$ exchange. J. Clin. Invest. 83:822-829.

37. Nara, Y., M. Kihara, T. Nabika, M. Mano, R. Horic, and Y. Yamori 1984. Dietary effect on platelet aggregation in men with and without a family history of essential hypertension. Hypertension (Dallas). 6:339-343.

38. LaPointe, M. S., and D. C. Batlle. $\mathrm{Na} / \mathrm{H}$ exchange activity and intracellular pH (ipH) in aortic vascular smooth muscle cells (VSMC) from SHR and WKY rats: role of $\mathrm{HCO}_{3} / \mathrm{CO}_{2}$. 1990. J. Am. Soc. Nephrol. 1:494.

39. Livne, A. A., O. Aharonozitz, and E. Paran. 1989. Higher $\mathrm{Na} / \mathrm{H}$ exchange rate and more alkaline intracellular $\mathrm{pH}$ set-point in essential hypertension: effect of protein kinase $\mathrm{C}$ modulation in platelets. J. Hypertens. 7:325-330. 